\title{
Evaluation of Traube's space using a novel computer-assisted method
}

\author{
Dündar Kaçar ${ }^{1}$, Çağatay Barut ${ }^{2}$ \\ ${ }^{1}$ Antalya Training and Research Hospital, Antalya, Turkey \\ ${ }^{2}$ Department of Anatomy, Faculty of Medicine, Bahçęsehir University, Istanbul, Turkey
}

\begin{abstract}
Objectives: Traube's space, used to detect spleen enlargement, is at the precordial area on the anterior wall of the chest. In this respect, correct assessment of this area during physical examination is very important. The aim of this study was to evaluate the area of Traube's space by percussion that is known to be sensitive and specific over $70 \%$ and assess effects of gender and defecation habit on the space area.

Methods: Thirty-four males and 32 females participated in the study, examined by the same physician. Traube's space was determined on the chest wall by percussion. Images of Traube's space were drawn on a transparent paper using certain reference points for each participant. All images were scanned and measurements were done by AutoCAD 2004 software. Weight and height of the individuals were also measured and their defecation information for the morning they participated in the study was also inquired.

Results: In the males, weight, height, body mass index (BMI) and Traube's space values were significantly higher than those of females $(p<0.05)$. There was a positive, strong and significant correlation between Traube's space and weight and height for the whole study group $(p<005)$. There were no statistically significant differences between these two groups when morning defecation was considered ( $p>0.05)$.

Conclusion: The results of this study may be useful for the evaluation of Traube's space and spleen enlargement during physical examination.
\end{abstract}

Keywords: percussion; physical examination; splenomegaly; Traube's space

Anatomy 2016;10(1):46-49 @2016 Turkish Society of Anatomy and Clinical Anatomy (TSACA)

\section{Introduction}

Traube's space is located on the left half of the anterior thoracic wall and is an area limited with the sixth costa, left anterior axillary line and left costal arch. ${ }^{[1]}$ In this space lies the fundus of the stomach. ${ }^{[2]}$ During percussion, a tympanic sound is produced due to this air-filled structure (Traube open). ${ }^{[3,4]}$ Once the spleen is enlarged, the sound reaches the Traube's space by passing through the front edge of the stomach and diaphragm ${ }^{[5]}$ and changes into a dull tone (Traube closed). ${ }^{[3]}$

Ludwig Traube (1818-1876), who had studies on this field, pointed out that the tympanic sound of this space may not be heard in various diseases. ${ }^{[1,6]}$ In the following years, various physical examination methods were devel- oped related to this field. In 1954, Nixon studied on this space by making patients lie on their right sides. ${ }^{[7]}$ Castell investigated the existence of spleen at the 8th and 9th intercostal distance by making the patients lie back in the supine position. ${ }^{[8,9]}$

The aim of this study was to determine the projection of this area on the front chest wall among healthy individuals and the average space it covers, and to evaluate the difference of its size by assessed by percussion between genders and individuals.

\section{Materials and Methods}

This cross-sectional study was carried out with the participation of 66 individuals (34 males, 32 females), aged 
between 18 to 35, who were second and third grade students of Zonguldak Karaelmas University, School of Medicine and staff of the same school. The Ethics Committee of Karaelmas University approved the study. Individuals taking part in the study were first given written and oral information regarding the study. Examinations were carried out by the same physician using the same method with the participant was lying in supine position and inhaling normally. The percussion started above the left breast by going down the mid-clavicular line and to the point where the tympanic sound heard was marked. Following the same line, the percussion was carried on down from the marked point, and the point where the tympanic sound disappeared was detected. With the same method, percussion was done transversely separately from the 6th and 7th intercostal spaces to the anterior axillary line, and from there percussion was done $2 \mathrm{~cm}$ laterally, and the points where the tympanic sound was first heard and then disappeared were marked. The distance between these six marked points was checked by percussion; the angle of combining line (straight, convex or concave) was found and highlighted with a permanent marker (Figure 1). Then, the drawing of this space was copied on a transparent paper.

In this study, the Castell method was preferred as a highly sensitive method in detecting the size of the spleen ${ }^{[1]}$ (Table 1). The areas were measured using using AutoCAD 2004 software (Mechanical Desktop Power Pack;
Microsoft, Redmond, WA, USA). In addition, the body weight and height of the participants were recorded and they were inquired if they ever had any stomach operations and defecation on the same morning. Body mass index (BMI) was calculated using the body weight / (height) ${ }^{2}$ formula. Data obtained from every participant was recorded in assessment forms and later transferred to SPSS for Windows, release 11.0.1 (SPSS Inc., Chicago, IL, USA; 2001). 2001). Independent samples test and MannWhitney $\mathrm{U}$ test were used to compare the data according to gender and to morning defecation, consequently. $\mathrm{p}<0.05$ was accepted to be statistically significant. Relation between the area of Traube's space and body weight, height and BMI were assessed using Pearson correlation analysis.

\section{Results}

In this study, the area of the Traube's space on the front chest was measured as $4688.89 \mathrm{~mm}^{2}$ in males and 2307.79 $\mathrm{mm}^{2}$ in females. The body weight, height, BMI and area values of the Traube's space of the male participants were higher than those of females, and the difference between them was statistically significant $(\mathrm{p}<0.05)$ (Table 2$)$.

Regarding female participants, no significant correlations were found among the parameters evaluated $(p>0.05)$. In males, there was a positive, strong and significant correlation between the area of the Traube's space and height $(\mathrm{r}=0.507, \mathrm{p}<0.05)$. In the whole study group, there was a positive, strong and significant correlation (a)

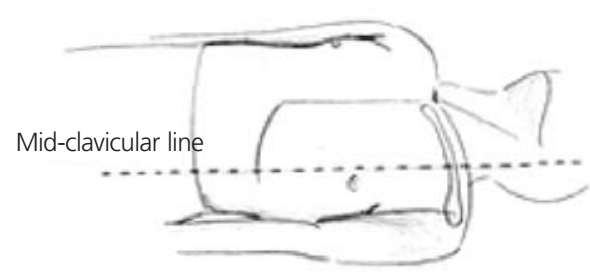

(c)

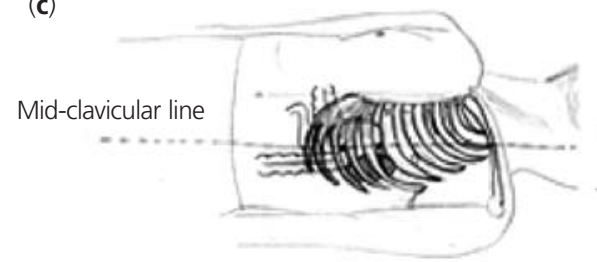

(e)

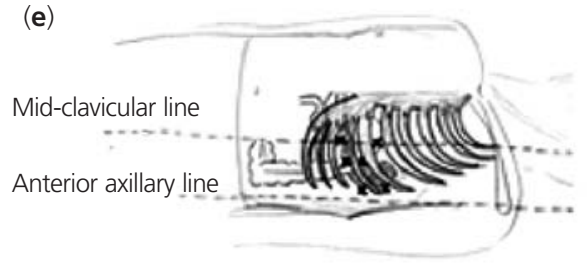

(b)

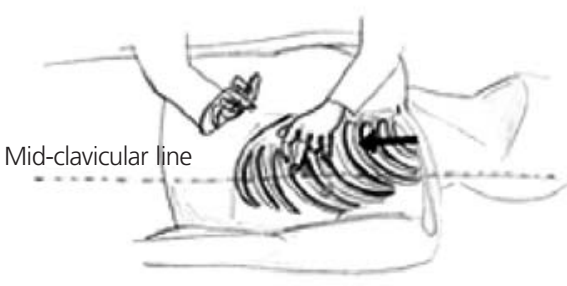

(d)
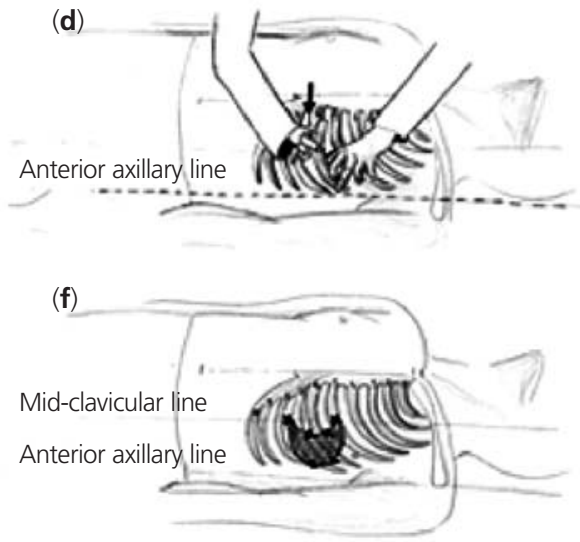

Figure 1. (a) Individual lying in supine position. (b) The percussion started above the left breast by going down the mid-clavicular line. (c) The point where the tympanic sound heard was marked. Following the same line, the percussion was carried on down from the marked point, and the point where the tympanic sound disappeared was detected. (d) With the same method, percussion was done transversely separately from the 6th and 7th intercostal spaces to the anterior axillary line and from there percussion was done $2 \mathrm{~cm}$ laterally. (e) The points where the tympanic sound was heard and then disappeared were marked. (f) The distance between these 6 marked points was checked by percussion; the angle of combining line (straight, convex or concave) was found and highlighted with a permanent marker. 
between the area of Traube's space and height $(\mathrm{r}=0.687)$ and weight $(\mathrm{r}=0.567)(\mathrm{p}<0.05)$; no significant relationship was detected between Traube's space and BMI $(\mathrm{p}>0.05)$ (Table 3). Forty-one participants had defecated in the morning and 25 had not; no statistically significant difference was found between the area values of the Traube's space of these two groups ( $>>0.05)$ (Table 4).

\section{Discussion}

Until now, studies on Traube's space mostly focused on the spleen size, and their main aim was to evaluate the sensitivity of the detection of Traube's space by physical examination in splenomegaly. ${ }^{[10-12]}$ In the Nixon method, the size of the spleen was evaluated by determining a reference point at a distance of $8 \mathrm{~cm}$ to the costal arc. ${ }^{[7]}$ In this study, instead of dealing with the relation between this space and the spleen, we aimed to detect the location of the space on the anterior thoracic wall, calculate the area and indicate the topographic anatomy of Traube's space. We found the area of the Traube's space as $4688.89 \mathrm{~mm}^{2}$ in males and $2307.79 \mathrm{~mm}^{2}$ in females (Table 2). In their study on the percussion of Traube's space, Barkun et al. ${ }^{[6]}$ found that when BMI increased, false-negative results also increased. In our study, the relation between BMI and Traube's space size was also evaluated, but no significant relation between these two was detected (Table 3).

In their study, Sullivan and Williams ${ }^{[10]}$ studied the change of the percussion sound by taking the left costal arch as a reference in the group lying on their right side, while taking the bottom intercostal distance of the left anterior axillary line as reference in the group lying back, in the supine position. In our study, we used the anterior axillary line, mid-clavicular line, costal arch and the 6th and 7th intercostal spaces on the left side as reference points. Sullivan and Williams ${ }^{[10]}$ pointed out that if splenomegaly was $40 \%$ over the spleen size, it could be palpated; however, if the spleen size was extremely big, it might not be detected. They also stated that every palpable spleen was not necessarily a sign of an abnormal situation, because palpable spleen can be found in 2-9\% of the normal population and $5-6 \%$ of the patient population. However, in their study, without investigating Traube's space, they focused on evaluation of the spleen size. In this study, we tried to detect the Traube's space by selecting more reference points for the calculation of its area. Nixon defined Traube's space as an area located between the 6th costa, lateral of the mid-axillary line and left costal arch. ${ }^{[7]}$ In our study, we defined Traube's space as an area between the 6th intercostal space, lateral of the anterior axillary line and the left costal arch. We believe that consideration of these values by physicians and keeping in mind that the values and the sizes of the spaces may differ according to gender (by minimizing the false-positive and false-negative evaluations) will be helpful to keep up the contribution of physical examination to diagnosis, therefore it will be beneficial for diagnoses where only physical examination is possible.

Table 1

Sensitivity and specifity of physical examination methods used in diagnosis of splenomegaly.

\begin{tabular}{lcc}
\hline Method & Sensitivity (\%) & Specifity (\%) \\
\hline Nixon $^{[7]}$ & 59 & 94 \\
Castell $^{[8]}$ & 82 & 83 \\
Barkun et al. $^{[6]}$ & 62 & 72 \\
\hline
\end{tabular}

Table 2

The comparison of Traube's space, body weight, height and BMI values according to gender using independent samples test.

\begin{tabular}{|c|c|c|c|c|c|c|c|}
\hline & \multicolumn{2}{|c|}{ Female $(n=32)$} & \multicolumn{2}{|c|}{ Male $(n=34)$} & \multirow[t]{2}{*}{$\mathbf{t}$} & \multirow[t]{2}{*}{ df } & \multirow[t]{2}{*}{$\mathbf{p}$} \\
\hline & Mean & SD & Mean & SD & & & \\
\hline $\begin{array}{l}\text { Area of Traube's } \\
\text { space }\left(\mathrm{mm}^{2}\right)\end{array}$ & 2307.79 & 1286.77 & 4688.89 & 1580.48 & -6.687 & 64 & 0 \\
\hline Body weight (kg) & 59.5 & 8.13 & 74.82 & 9.42 & -7.054 & 64 & 0 \\
\hline Height (m) & 1.64 & 0.06 & 1.78 & 0.06 & -8.735 & 64 & 0 \\
\hline BMI $\left(\mathrm{kg} / \mathrm{m}^{2}\right)$ & 22.1 & 2.92 & 23.65 & 2.66 & -2.266 & 64 & 0.027 \\
\hline
\end{tabular}

Table 3

The relation between the area of Traube's space and BMI, height and weight using Pearson correlation analysis.

\begin{tabular}{|c|c|c|c|c|}
\hline & & $\begin{array}{c}\text { Female } \\
(\mathrm{n}=32) \\
\text { Traube's space }\end{array}$ & $\begin{array}{c}\text { Male } \\
(n=34) \\
\text { Traube's space }\end{array}$ & $\begin{array}{c}\text { Total } \\
(n=66) \\
\text { Traube's space }\end{array}$ \\
\hline \multirow[t]{2}{*}{ BMI } & $r$ & 0.026 & 0.010 & 0.187 \\
\hline & $p$ & 0.888 & 0.954 & 0.132 \\
\hline \multirow[t]{2}{*}{ Height } & $r$ & 0.267 & 0.507 & 0.682 \\
\hline & $p$ & 0.139 & 0.002 & 0 \\
\hline \multirow[t]{2}{*}{ Body weight } & $r$ & 0.173 & 0.298 & 0.567 \\
\hline & $p$ & 0.343 & 0.087 & 0 \\
\hline
\end{tabular}

Table 4

The comparison of Traube's space and other parameters according to morning defecation using Mann-Whitney $\mathrm{U}$ test.

\begin{tabular}{lcclccc}
\hline \multirow{2}{*}{ Morning defecation } & \multicolumn{2}{c}{ Yes $(\mathbf{n}=\mathbf{2 5})$} & & \multicolumn{2}{c}{ No $(\mathbf{n}=\mathbf{4 1})$} & \multirow{2}{*}{$\mathbf{p}$} \\
\cline { 2 - 3 } & Mean & SD & & Mean & SD & \\
\hline $\begin{array}{l}\text { Traube's space } \\
\text { area }\left(\mathrm{mm}^{2}\right)\end{array}$ & 4145.57 & 2082.65 & & 3161.76 & 1643.88 & 0.065 \\
Body weight $(\mathrm{kg})$ & 70.68 & 12.69 & & 65.39 & 10.67 & 0.097 \\
Height $(\mathrm{m})$ & 1.73 & 0.09 & & 1.70 & 0.09 & 0.330 \\
BMl $\left(\mathrm{kg} / \mathrm{m}^{2}\right)$ & 25.53 & 2.77 & & 22.52 & 2.88 & 0.117 \\
\hline
\end{tabular}




\section{Acknowledgements}

We would like to express our sincere gratitude to Dr. Derya Karaoğlu for her exquisite drawings.

\section{References}

1. Yang JC, Rickman LS, Bosser SK. The clinical diagnosis of splenomegaly. West J Med 1991;155:47-52.

2. Yıldırım M. Topografik anatomi. İstanbul: Nobel Tip Kitabevi; 2000. p. 283.

3. Ökten A. Karnın fizik muayenesi. In: Kaysı A, ed. İç hastalıkları (Semiyoloji). 4. baskı. İstanbul: Alfa Yayınları; 2007. p. 426.

4. Korkut B, Altınbaş A, Sarı̈uzzel A, Özergin U, Gök H. Discrete type subaortic stenosis in a patient who had dextrocardia with situs inversus totalis. Int J Angiol 1998;7:258-60.

5. Arıncı K, Elhan A. Anatomi. 2. cilt. 4. baskı, Ankara: Güneş Kitabevi; 2006. p. 105.
6. Barkun AN, Camus M, Meagher T, Green L, Coupal L, De Stempel J, Grover SA. Splenic enlargement and Traube's space: how useful is percussion? Am J Med 1989;87:562-6.

7. Nixon RK Jr. The detection of splenomegaly by percussion. N Engl J Med 1954;250:166-7.

8. Castell DO. The spleen percussion sign. A useful diagnostic technique. Ann Intern Med 1967;67:1265-7.

9. Castell DO, O'Brien KD, Muench H, Chalmers TC. Eastimation of liver size by percussion in normal individuals. Ann Intern Med 1969;70:1183-9.

10. Sullivan S, Williams R. Reliability of clinical techniques for detecting splenic enlargement. Br Med J 1976;2:1043-4.

11. Zhang B, Lewis SM. A study of the reliability of clinical palpation of the spleen. Clin Lab Haematol 1989;11:7-10.

12. Grover SA, Barkun AN, Sackett DL. The rational clinical examination. Does this patient have splenomegaly? JAMA 1993;270:221821.

Correspondence to: Çağatay Barut, MD, PhD

Department of Anatomy, Faculty of Medicine,

Bahçeşehir University, Istanbul, Turkey

Phone: +90 5324638471

e-mail: cagbarut@yahoo.com

Conflict of interest statement: No conflicts declared.

\footnotetext{
This is an open access article distributed under the terms of the Creative Commons Attribution-NonCommercial-NoDerivs 3.0 Unported (CC BY-NCND3.0) Licence (http://creativecommons.org/licenses/by-nc-nd/3.0/) which permits unrestricted noncommercial use, distribution, and reproduction in any medium, provided the original work is properly cited. Please cite this article as: Kaçar D, Barut Ç. Evaluation of Traube's space using a novel computer assisted method. Anatomy 2016;10(1):46-49.
} 